06.3

\title{
Скорость горения порошкообразного пористого кремния в условиях ограниченного пространства
}

\author{
(ㄷ Г.Г. Савенков ${ }^{1,2}$, А.И. Козачук ${ }^{1}$, У.М. Побережная ${ }^{1,2}$, В.М. Фрейман ${ }^{1}$, Г.Г. Зегря ${ }^{1}$ \\ ${ }^{1}$ Физико-технический институт им. А.Ф. Иоффре РАН, Санкт-Петербург, Россия \\ ${ }^{2}$ Санкт-Петербургский государственный технологический институт (Технический университет), Санкт-Петербург, Россия \\ E-mail: sav-georgij@yandex.ru
}

Поступило в Редакцию 16 августа 2021 г.

В окончательной редакции 2 ноября 2021 г.

Принято к публикации 2 ноября 2021 г.

\begin{abstract}
Описывается методика определения скорости горения порошкообразного пористого кремния в условиях ограниченного пространства. Определено, что значения скоростей горения пористого кремния близки к значениям скоростей быстрогорящих взрывчатых веществ.
\end{abstract}

Ключевые слова: пористый кремний, скорость горения.

DOI: 10.21883/PJTF.2022.04.52076.18994

Пористый кремний с размером пор от нескольких нанометров до нескольких десятков и сотен нанометров в настоящее время считается одним из наиболее перспективных материалов для применения в таких областях науки и техники, как фармакология, электроника и оптоэлектроника, производство взрывчатых материалов [1-3] и др. Одним из возможных видов практического применения пористого кремния является изготовление самоуничтожающихся кремниевых чипов [4]. Самоуничтожение чипов возможно как путем горения, так и путем взрыва. В последнем случае необходим некий слой определенной толщины, пропитанный окислителем. Взрыв данного слоя и приводит к уничтожению собственно чипа. Самоуничтожение в процессе горения вполне возможно и без пропитки слоя специальным окислителем, так как имеются сведения [5], что пористый кремний горит за счет кислорода воздуха.

Для определения возможности применения процесса самоуничтожения чипа путем сгорания необходима корректная оценка скорости горения пористого кремния в условиях ограниченного пространства, т.е. по сути только за счет кислорода воздуха, находящегося в порах кремния. К сожалению, в подавляющем большинстве работ если и приводятся данные по скорости горения (взрывчатого превращения) пористого кремния, то они относятся к пористому кремнию, пропитанному различными окислителями [6,7]. Экспериментальная оценка скорости горения пластинки пористого кремния толщиной менее $100 \mu \mathrm{m}$ (что, собственно, и представляет практический интерес) затруднена. Это объясняется невозможностью одновременного обеспечения отсутствия воздуха вне пор и цифровой регистрации процесса горения с получением численных значений скорости.
Поэтому в настоящей работе применен следующий алгоритм проведения экспериментов по определению скорости горения пористого кремния.

1. Из пластины толщиной $\sim 250 \mu \mathrm{m}$ монокристаллического кремния (марка КДБ-100) с высоким уровнем легирования бором ( $p$-типа) порядка $1.1 \cdot 10^{19} \mathrm{~cm}^{-3}$ в гальваностатическом режиме были получены слои пористого кремния путем двустороннего электрохимического травления. В качестве электролита использовалась смесь равных объемов плавиковой кислоты (48\% $\mathrm{HF)} \mathrm{и} \mathrm{этилового} \mathrm{спирта.} \mathrm{Электрохимическое} \mathrm{травле-}$ ние позволяет получать однородные механически стабильные пластины высоколегированного кремния $p$ - и $n$-типов проводимости пористостью до $\sim 75 \%$ (поры сквозные, диаметр 20-35 nm). Структура таких слоев формируется системой ветвящихся пор, распространяющихся преимущественно вдоль кристаллографических направлений $\langle 100\rangle$. Таким образом, по классификации Международного союза по чистой и прикладной химии (IUPAC) исследуемый нами пористый кремний относится к мезопористым структурам. Более подробно технология получения пористого кремния изложена нами в работах $[2,5,8,9]$.

2. Полученная пластина пористого кремния перемалывалась вручную в порошок с размером частиц 30-40 $\mu \mathrm{m}$. Изображение частицы порошка, полученное с помощью сканирующей электронной микроскопии (СЭМ), приведено на рис. 1.

3. Порошок помещался в колпачок с внешним диаметром $d_{s}=8.0 \mathrm{~mm}$. Сверху колпачок закрывался алюминиевой фольгой толщиной $40 \mu \mathrm{m}$, и через фольгу производилось прессование порошка до высоты $1 \mathrm{~mm}$, что обеспечивало плотное прилегание фольги к навеске порошка и сводило к минимуму количество воздуха между порошком и фольгой.

4. Колпачок помещался между двумя стержнями (являвшимися аналогом разрезного стержня Гопкинсо- 


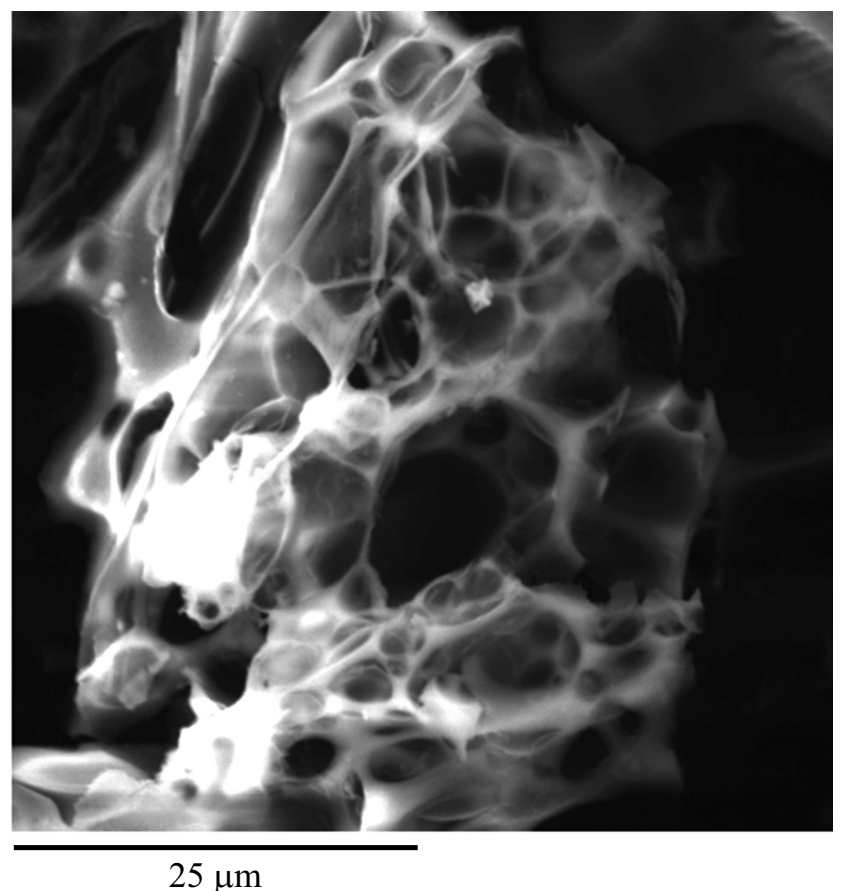

Рис. 1. СЭМ-изображение частицы порошка пористого кремния.

на [2]), на одном из которых (называемом измерительным стержнем) находился тензодатчик (рис. 2). Со стороны алюминиевой фольги устанавливался нихромовый фольговый мостик (тепловой инициатор), через который пропускался электрический ток. В результате нагрева нихромового мостика происходило инициирование процесса горения в запрессованном порошке пористого кремния.

5. Горение пористого кремния приводило к образованию продуктов горения, которые создавали давление, фиксация которого осуществлялась с помощью тензодатчика. Примеры осциллограмм, снимаемых с тензодатчика, приведены на рис. $3, a$ и $b$. Отметим, что заполнение пор кремния окислителем, например перхло- ратом кальция, приводило к взрывчатому превращению более высокого порядка, чем послойное горение, и на осциллограмме появлялся резкий пик (рис. 3,c).

Расчет амплитуды механических напряжений, сопровождающих вызванную взрывом волну деформаций в стержне, проводился по формуле

$$
\sigma=\frac{\Delta U E S_{1}}{I R_{0} k S_{0}}
$$

где $\Delta U-$ импульс напряжения на осциллограмме, $I=15 \mathrm{~mA}$ - ток в тензодатчиках, $R_{0}=200 \Omega-$ сопротивление тензометров, $E=200 \mathrm{GPa}$ - модуль Юнга материала измерительного стержня и опорного стержня (закаленные стали), $k=2$ - коэффициент тензочувствительности, $S_{1}$ - площадь сечения измерительного стержня, $S_{0}$ - площадь торцевой поверхности образца.

Максимальные значения давления при горении пористого кремния для рис. $3, a$ составляли $26 \mathrm{MPa}$, для рис. $3, b-22 \mathrm{MPa}$. Максимальное давление взрывного процесса на рис. 3, с-233 МРа.

Из осциллограмм на рис. 3 следует, что скорость горения пористого кремния на рис. $3, a \sim 20 \mathrm{~mm} / \mathrm{s}$, на рис. $3, b \sim 25 \mathrm{~mm} / \mathrm{s}$. Такие значения скоростей горения близки к значениям скоростей быстрогорящих взрывчатых веществ, например пикрата калия, стифната свинца и др. [10], и более чем на порядок превышают скорость горения наноразмерного порошка меди $(1.3 \pm 0.3 \mathrm{~mm} / \mathrm{s})$ [11]. Но полученные значения скоростей горения пористого кремния на порядки ниже скоростей горения пористого кремния, пропитанного различными окислителями, которые находятся в диапазоне от 0.1 до более $3500 \mathrm{~m} / \mathrm{s}$ [12]. Крайние значения правого диапазона, конечно, относится уже к скоростям детонации.

Таким образом, показано, что пористый кремний в ограниченном объеме может воспламеняться. Инициирование горения может осуществляться внешним источником тепла (раскаленной проволокой). При этих условиях скорость горения пористого кремния составляет $20-25 \mathrm{~mm} / \mathrm{s}$. К сожалению, проведенные иссле-

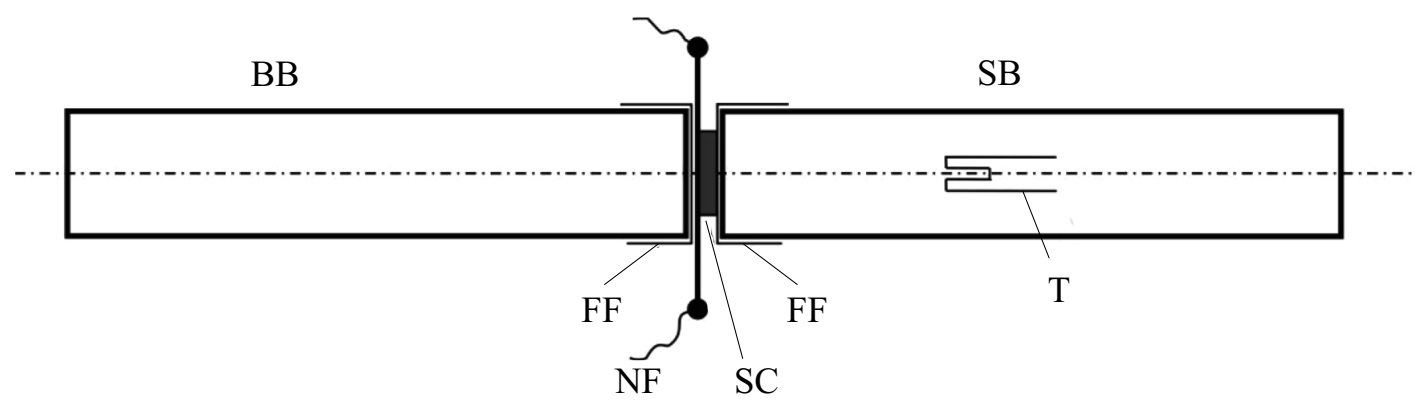

Рис. 2. Схематическое изображение образца, закрепленного между двумя мерными стержнями тензодатчика. SB - измерительный стержень с тензометрическим датчиком Т $(d=8 \mathrm{~mm}), \mathrm{BB}$ - опорный стержень $(d=8 \mathrm{~mm}), \mathrm{SC}-$ колпачок с пористым кремнием, $\mathrm{FF}$ - фторопластовая пленка толщиной $100 \mu \mathrm{m}, \mathrm{NF}$ - нихромовая фольга (тепловой инициатор). 


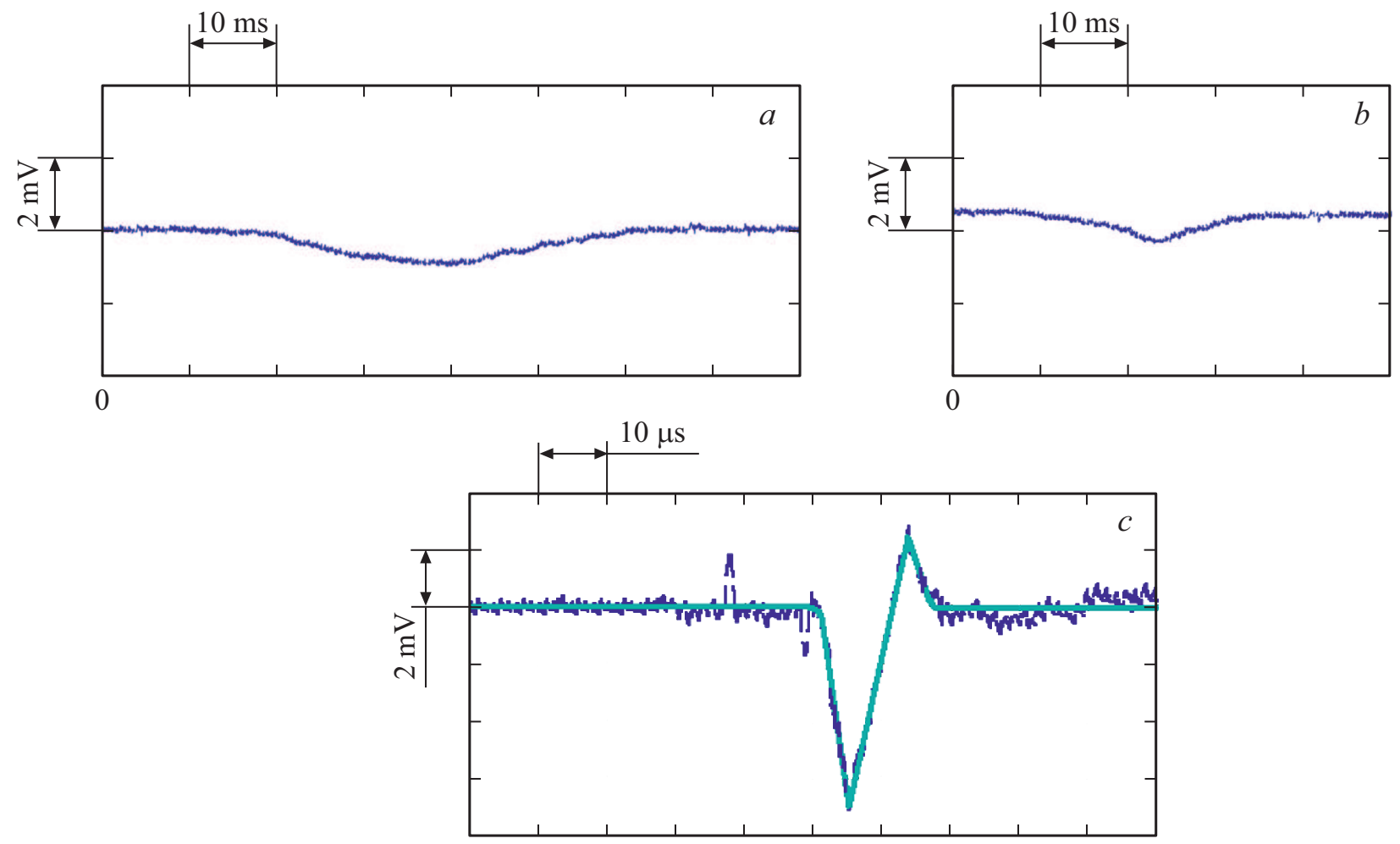

Рис. 3. Примеры осциллограмм давления при горении пористого кремния без окислителя $(a, b)$ и при участии окислителя перхлората кальция $(c)$.

дования не дают возможности установить, в какой форме происходит горение: в конвективной или кондуктивной. Можно полагать, что с большей долей вероятности оно проходит все же в кондуктивной форме.

\section{Конфликт интересов}

Авторы заявляют, что у них нет конфликта интересов.

\section{Список литературы}

[1] О.И. Ксенофонтова, А.В. Васин, В.В. Егоров, А.В. Бобыль, Ф.Ю. Солдатенков, Е.И. Теруков, В.П. Улин, Н.В. Улин, О.И. Киселев, ЖТФ, 84 (1), 67 (2014). [O.I. Ksenofontova, A.V. Vasin, V.V. Egorov, A.V. Bobyl', F.Yu. Soldatenkov, E.I. Terukov, V.P. Ulin, N.V. Ulin, O.I. Kiselev, Tech. Phys., 59 (1), 66 (2014). DOI: 10.1134/S1063784214010083].

[2] Г.Г. Савенков, А.Г. Зегря, Г.Г. Зегря, Б.В. Румянцев, А.Б. Синани, Ю.М. Михайлов, ЖТФ, 89 (3), 397 (2019). DOI: $10.21883 /$ JTF.2019.03.47175.271-18 [G.G. Savenkov, A.G. Zegrya, G.G. Zegrya, B.V. Rumyantsev, A.B. Sinani, Yu.M. Mikhailov, Tech. Phys., 64 (3), 361 (2019). DOI: $10.1134 / \mathrm{S} 1063784219030204]$.

[3] М.В. Агеев, Ю.Н. Ведерников, Г.Г. Зегря, У.М. Побережная, В.К. Попов, Г.Г. Савенков, Письма в ЖТФ, $46 \quad$ (5), 48 (2020). DOI: 10.21883/PJTF.2020.05.49110.18144 [M.V. Ageev, Yu.N. Vedernikov, G.G. Zegrya, U.M. Poberezhnaya,
V.K. Popov, G.G. Savenkov, Tech. Phys. Lett., 46 (3), 249 (2020). DOI: 10.1134/S1063785020030037].

[4] С.К. Лазарук, А.В. Долбик, В.А. Лабунов, В.Е. Борисенко, ФТП, 41 (9), 1130 (2007). [S.K. Lazaruk, A.V. Dolbik, V.A. Labunov, V.E. Borisenko, Semiconductors, 41 (9), 1113 (2007). DOI: 10.1134/S1063782607090175].

[5] Г.Г. Зегря, Г.Г. Савенков, В.А. Морозов, А.Г. Зегря, Н.В. Улин, В.П. Улин, А.А. Лукин, В.А. Брагин, И.А. Оськин, Ю.М. Михайлов, ФТП, 51 (4), 501 (2017). DOI: 10.21883/FTP.2017.04.44342.8391 [G.G. Zegrya, G.G. Savenkov, V.A. Morozov, A.G. Zegrya, N.V. Ulin, V.P. Ulin, A.A. Lukin, V.A. Bragin, I.A. Oskin, Yu.M. Mikhailov, Semiconductors, 51 (4), 477 (2017). DOI: $10.1134 / \mathrm{S} 106378261704025 \mathrm{X}$.

[6] M. du Plessis, Propellants Explos. Pyrotech., 39 (3), 348 (2014).

[7] A. Abraham, N.W. Piekiel, C.J. Morris, E.L. Dreizin, Propellants Explos. Pyrotech., 41 (1), 179 (2016).

[8] Г.Г. Зегря, В.П. Улин, А.Г. Зегря, Н.В. Улин, В.М. Фрейман, Ю.М. Михайлов, ЖТФ, 89 (10), 1575 (2019). DOI: $10.21883 /$ JTF.2019.10.48175.91-19

[G.G. Zegrya, V.P. Ulin, A.G. Zegrya, N.V. Ulin, Yu.M. Mikhailov, Tech. Phys., 64 (10), 1492 (2019). DOI: $10.1134 / \mathrm{S} 1063784219100268]$.

[9] А.Г. Зегря, В.В. Соколов, Г.Г. Зегря, Ю.В. Ганин, Ю.М. Михайлов, Письма в ЖТФ, 45 (21), 3 (2019). $\quad$ DOI: $\quad 10.21883 /$ PJTF.2019.21.48463.17791 [A.G. Zegrya, V.V. Sokolov, G.G. Zegrya, Yu.V. Ganin, Yu.M. Mikhailov, Tech. Phys. Lett., 45 (11), 1067 (2019). DOI: $10.1134 / \mathrm{S} 1063784219100268]$. 
[10] К.К. Андреев, А.Ф. Беляев, Теория взрывчатых веществ (Оборонгиз, М., 1960).

[11] М.И. Алымов, Н.М. Рубцов, Б.С. Сеплярский, Волны горения в конденсированных средах: инищиирование, критические явления, размерные эфбекты (РАН, М., 2020).

[12] Ph.M. Guerieri, B. Fuchs, W.A. Churaman, Propellants Explos. Pyrotech., 46 (8), 1260 (2021).

DOI: $10.1002 /$ prep.202000311 